\title{
(6) OPEN ACCESS \\ Improvements in productivity at paid work and within the household, and increased participation in daily activities after 24 weeks of certolizumab pegol treatment of patients with psoriatic arthritis: results of a phase 3 double-blind randomised placebo-controlled study
}

\author{
A Kavanaugh, ${ }^{1}$ D Gladman, ${ }^{2}$ D van der Heijde, ${ }^{3}$ O Purcaru, ${ }^{4}$ P Mease ${ }^{5}$
}

\begin{abstract}
Handling editor Tore K Kvien
${ }^{1}$ Division of Rheumatology, Allergy and Immunology, UCSD, San Diego, California USA

${ }^{2}$ Division of Health Care \& Outcomes Research, Toronto Western Research Institute, Toronto Western Hospital, Toronto, Ontario, Canada ${ }^{3}$ Department of Rheumatology, Leiden University Medical Centre, Leiden, Netherlands ${ }^{4}$ UCB Pharma, Brussels, Belgium

${ }^{5}$ Swedish Medical Center and University of Washington, Seattle, Washington, USA
\end{abstract}

\section{Correspondence to} Professor Arthur Kavanaugh, Division of Rheumatology, Allergy and Immunology, University of California, San Diego, 9500 Gilman Drive, MC 0943, La Jolla CA 920370943, USA;

akavanaugh@ucsd.edu

Received 7 January 2014 Revised 15 April 2014 Accepted 24 May 2014 Published Online First 18 June 2014

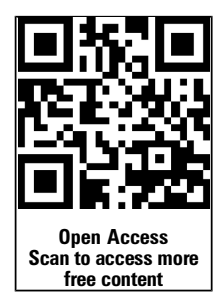

CrossMark

To cite: Kavanaugh $A$ Gladman D, van der Heijde D, et al. Ann Rheum Dis 2015;74:44-51.

\section{ABSTRACT}

Objectives To evaluate the effect of certolizumab pegol (CZP) on productivity outside and within the home, and on participation in family, social and leisure activities in adult patients with psoriatic arthritis (PSA). Methods RAPID-PSA (NCT01087788) is a phase 3, double-blind, placebo-controlled trial. 409 patients with active PsA were randomised 1:1:1 to placebo, CZP 200 mg every 2 weeks (Q2W) or CZP 400 mg every 4 weeks (Q4W). The arthritis-specific Work Productivity Survey (WPS) assessed the impact of PsA on paid work and household productivity, and participation in social activities during the preceding month. WPS responses were compared between treatment arms using a nonparametric bootstrap-t method.

Results At baseline, 56.6\%, 60.1\% and $61.5 \%$ of placebo, CZP $200 \mathrm{mg}$ Q2W and CZP $400 \mathrm{mg}$ Q4W patients were employed. By week 24, employed CZP patients reported an average of 1.0-1.8 and 3.0-3.9 fewer days of absenteeism and presenteeism, respectively, per month compared with 1.0 and 0.3 fewer days for placebo patients $(p<0.05)$. Within the home, by week 24, CZP patients reported an average of 3.0-3.5 household work days gained per month versus 1.0 day for placebo $(p<0.05)$. CZP patients also reported fewer days with reduced household productivity or days lost for participation in family, social and leisure activities. Improvements with CZP were seen as early as week 4 and continued to week 24 .

Conclusions CZP treatment significantly improved productivity at paid work and within the home, and resulted in greater participation in social activities for PsA patients. Trial registration number NCT01087788.

\section{INTRODUCTION}

Psoriatic arthritis (PsA) is a chronic inflammatory arthritis which affects up to $30 \%$ of patients with psoriasis. ${ }^{1-3}$ Over half of the patients with PsA will go on to exhibit a more severe, erosive form of the disease that can be associated with rapidly progressive joint damage and substantial functional impairment. ${ }^{4-6}$ The complex nature of PsA can also result in a considerable negative impact on multiple physical and emotional aspects of patients' $\operatorname{lives}^{7}{ }^{8}$ as well as severe work disability and loss of productivity. ${ }^{9}$ This has a significant impact on the quality of life as well as financial status of individuals.

While there is published evidence on the burden of the disease on work disability in related rheumatic diseases such as rheumatoid arthritis (RA) and ankylosing spondylitis (AS), ${ }^{10-13}$ to date there are few data on work disability in PsA. ${ }^{9}{ }^{14}$ Some evidence indicates that the employment rate in patients with PsA is significantly lower than that seen in the general population, slightly lower than in the AS population but higher than in the RA population. ${ }^{15}$

In contrast to RA, very little is known about the indirect costs associated with PsA and its treatment. The age of onset of PsA is in the 30-40s for men and women, an age at which many men and women would be in the midst of working careers. Additionally, two separate studies to identify issues of concern among PsA patients reported the reduced ability to work or volunteer ${ }^{16}$ and the reduced ability to fulfil personal roles, social life and work, as common concerns. ${ }^{17}$ Reports from several studies of tumour necrosis factor (TNF) inhibitor in PsA have suggested that these biologic agents can have a positive impact on productivity in PsA patients, improving employment status and work productivity compared to placebo. ${ }^{18-20}$ However, further research is required to better understand the impact of PsA and TNF inhibitor therapies on workplace productivity, as well as on daily activities within the household and participation in social or leisure activities.

The efficacy and safety of certolizumab pegol (CZP), a PEGylated Fc-free anti-TNF agent, in PsA patients has been investigated and reported in the RAPID-PsA trial (NCT01087788). ${ }^{21}$ Here we report on the impact of CZP on productivity in paid and household work, and on participation in family, social and leisure activities, in patients with active PsA.

\section{METHODS \\ Patients}

The RAPID-PsA trial (NCT01087788) randomised 409 patients aged 18 years or older, with a diagnosis of adult-onset active PsA of $\geq 6$ months' duration 
as defined by the ClASsification criteria for Psoriatic ARthritis (CASPAR). ${ }^{22}$ All recruited patients had to have active psoriatic skin lesions or a documented history of psoriasis. In addition, erythrocyte sedimentation rate $\geq 28 \mathrm{~mm} / \mathrm{h}$ (Westergren) or C-reactive protein levels above the upper limit of normal (ULN; $7.9 \mathrm{mg} / \mathrm{L}$ ) was required. Patients must have previously failed treatment with, or been resistant to, at least one disease modifying antirheumatic drug and up to $40 \%$ of patients could have previously been treated with a TNF inhibitor.

Patients were excluded from the study if they had a form of inflammatory arthritis other than PsA or had a secondary, noninflammatory condition symptomatic enough to interfere with evaluation of CZP for PsA. Patients were also excluded if they had received previous treatment for PsA or psoriasis with more than two biologics or at least two TNF inhibitors, or had primary failure to a prior TNF inhibitor.

\section{Study design}

RAPID-PsA is an ongoing, phase 3, multicentre study in PsA patients. Details of the RAPID-PsA trial design are reported elsewhere. $^{21}$ In brief, the study was double-blind and placebocontrolled to week 24, dose-blind to week 48 and is open-label to week 216. Patients were randomised 1:1:1 to placebo, or $400 \mathrm{mg}$ CZP at weeks 0, 2 and 4 (loading dose) followed by either $200 \mathrm{mg}$ CZP every 2 weeks (Q2W) or $400 \mathrm{mg}$ CZP every 4 weeks (Q4W), administered subcutaneously by investigators using a blinded prefilled syringe. ${ }^{21}$ Randomisation was stratified according to investigator site and prior TNF inhibitor exposure according to an interactive voice response system.

Placebo patients who failed to achieve a $10 \%$ improvement from baseline in tender and swollen joint counts at weeks 14 and 16 underwent mandatory escape and were re-randomised at week 16 to receive CZP $200 \mathrm{mg}$ Q2W or CZP $400 \mathrm{mg}$ Q4W following loading dose at weeks 16, 18 and 20. The clinical primary endpoints were ACR20 response at week 12 and change from baseline in modified Total Sharp Score (mTSS) at week $24 .^{2123} \mathrm{CZP}$ safety was also investigated and is reported elsewhere. $^{21}$

\section{Work Productivity Survey}

The Work Productivity Survey (WPS) is a novel validated questionnaire assessing the impact of arthritis-related symptoms on patient productivity in the workplace and at home, and on participation in family, social and leisure activities. ${ }^{24}$ The WPS has demonstrated good psychometric properties (ie, discriminant validity, responsiveness to clinical changes and reliability) in $\mathrm{RA},{ }^{25} \mathrm{PsA}^{26}$ and axial spondyloarthritis (axSpA) (unpublished data).

The WPS is self-reported, but interviewer-administered and has a recall period of 1 month. The first question addresses employment status and provides additional information on job type for employed patients (non-manual, manual with no supervisory duties, or mixed) and on the status of those not employed. For employed patients, three questions relate to paid work productivity outside the home. These questions assess over the past month: absenteeism (full days of work missed due to arthritis); presenteeism (days with work productivity reduced by $\geq 50 \%$ due to arthritis); and the level of interference of arthritis on work productivity (on a $0-10$ scale; where $0=$ no interference and $10=$ complete interference).

All patients, regardless of their employment status, answer five questions which are related to household work and daily activities. These questions specifically assess over the previous month: the number of days with no household work performed due to arthritis; days with household productivity reduced by $\geq 50 \%$ due to arthritis; days with outside help hired due to arthritis; days with family, social or leisure activities missed due to arthritis; and the level of arthritis interference with household productivity (on a $0-10$ scale; where $0=$ no interference and $10=$ complete interference). The WPS was completed at the

Table 1 RAPID-PsA baseline demographics and disease characteristics at study baseline (RS population, observed cases)

\begin{tabular}{|c|c|c|c|c|}
\hline & $\begin{array}{l}\text { Placebo } \\
(n=136)\end{array}$ & $\begin{array}{l}\text { CZP } \\
200 \mathrm{mg} \text { Q2W } \\
(\mathrm{n}=138)\end{array}$ & $\begin{array}{l}\text { CZP } \\
400 \mathrm{mg} \text { Q4W } \\
(\mathrm{n}=135)\end{array}$ & $\begin{array}{l}\text { All patients } \\
(\mathrm{N}=409)\end{array}$ \\
\hline \multicolumn{5}{|l|}{ Demographic characteristics* } \\
\hline Age, years & $47.3 \pm 11.1$ & $48.2 \pm 12.3$ & $47.1 \pm 10.8$ & $47.6 \pm 11.4$ \\
\hline Sex, \% female & 58.1 & 53.6 & 54.1 & 55.3 \\
\hline Weight, kg & $82.6 \pm 19.9 \dagger$ & $85.8 \pm 17.7$ & $84.8 \pm 18.7$ & $84.4 \pm 18.8 \ddagger$ \\
\hline $\mathrm{BMI}, \mathrm{kg} / \mathrm{m}^{2}$ & $29.2 \pm 6.7 \dagger$ & $30.5 \pm 6.2$ & $29.6 \pm 6.6$ & $29.8 \pm 6.5 \ddagger$ \\
\hline \multicolumn{5}{|l|}{ Arthritis characteristics } \\
\hline Tender joint count (0-68 joints) & $19.9 \pm 14.7$ & $21.5 \pm 15.3$ & $19.6 \pm 14.8$ & $20.3 \pm 14.9$ \\
\hline Swollen joint count (0-66 joints) & $10.4 \pm 7.6$ & $11.0 \pm 8.8$ & $10.5 \pm 7.5$ & $10.7 \pm 8.0$ \\
\hline Physician's assessment of disease activity, by VAS, mm & $58.7 \pm 18.7$ & $56.8 \pm 18.2$ & $58.2 \pm 18.9$ & $57.9 \pm 18.6$ \\
\hline \multicolumn{5}{|l|}{ Psoriasis characteristics } \\
\hline Psoriasis BSA $\geq 3 \%, n(\%)$ & $86(63.2)$ & $90(65.2)$ & $76(56.3)$ & $252(61.6)$ \\
\hline PASI, median (min-max)§ & $7.1(0.3-55.2)$ & $6.8(0.6-72.0)$ & $8.1(0.6-51.8)$ & $7.2(0.3-72.0)$ \\
\hline \multicolumn{5}{|l|}{ Concomitant medication } \\
\hline MTX use, \% & 61.8 & 63.8 & 65.2 & 63.6 \\
\hline CS use, $\%$ & 28.7 & 36.2 & 25.9 & 30.0 \\
\hline \multicolumn{5}{|c|}{$\begin{array}{l}\text { There were no significant differences between treatment groups at baseline. } \\
{ }^{*} \text { Except where indicated otherwise, values are the mean } \pm \text { SD. } \\
t \mathrm{n}=135 \text {. } \\
\text { Fn=408. } \\
\text { §PASI scores for those patients with psoriasis body surface area } \geq 3 \% \text { at baseline. } \\
\text { १Refers to concomitant use of MTX or any CS taken for at least } 1 \text { day during the } 24 \text {-week double-blind treatment period. } \\
\text { BMI, body mass index; BSA, body surface area; CS, corticosteroid; CZP, certolizumab pegol; MTX, methotrexate; PASI, Psoriasis Area and Severity Index; Q2W, every } 2 \text { weeks; Q4W, } \\
\text { every } 4 \text { weeks; RS, randomised set; VAS, visual analogue scale. }\end{array}$} \\
\hline
\end{tabular}


- Employed (non-manual job)

口Employed (manual job with no supervisory duties)

- Retired

- Other non-employed

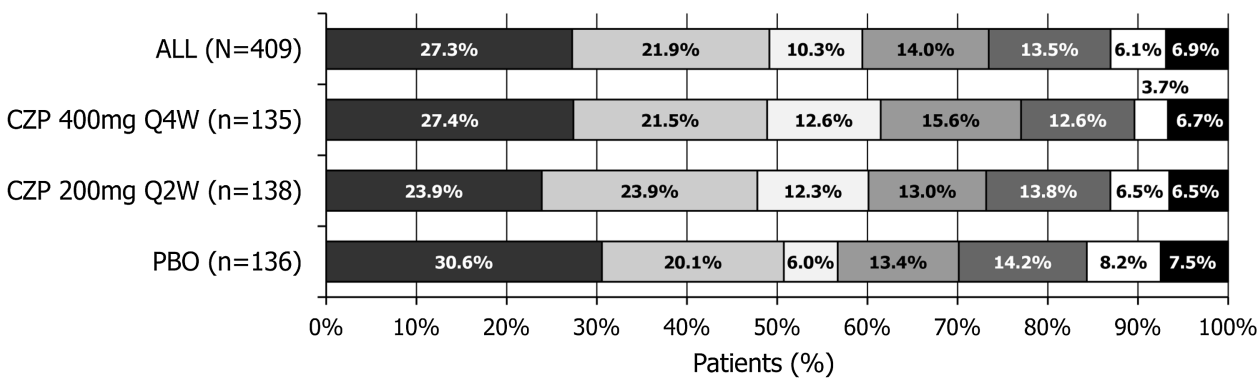

Employed (mixed job: non-manual/manual)

Unable to work due to arthritis

口Homemaker
Patients (\%)

Figure 1 RAPID-PsA: employment status at study baseline (randomised set population, observed cases). Other non-employed includes: student, unable to work due to non-arthritis and other non-employed status. CZP, certolizumab pegol; PBO, placebo; Q2W, every 2 weeks; Q4W, every 4 weeks.

baseline visit of the RAPID-PsA trial and every subsequent 4 weeks.

\section{Statistical analysis}

All analyses were conducted in the randomised set (RS), which included all patients randomised to the study. The RS has also been used to report clinical and patient-reported efficacy outcomes from the RAPID-PsA study in previous publications. ${ }^{21} 27$ The WPS questions relating to workplace productivity were analysed for employed patients only, whereas the questions assessing household productivity were analysed for all patients, in the entire RS.

The burden of PsA on productivity in the workplace and within the home was assessed through the WPS responses at study baseline in the entire RS population, as well as by treatment groups. Mean WPS responses were compared between CZP and placebo treatment arms at specific study visits using a non-parametric bootstrap-t test (a 5\% statistical significance level was used). ${ }^{28}$ Last observation carried forward (LOCF) was used to impute missing data following patient withdrawal (for any reason) or for any patient with a missing measurement. For placebo patients who escaped to active treatment arms, the last observation prior to escape was carried forward.

Additional post-hoc analyses were conducted to calculate the frequency distribution of the WPS scores at specific visits and the cumulative gains over 24 weeks. Cumulative productivity scores were derived for each individual treatment group by summing the productivity scores over the 24 weeks of the double-blind phase, starting at week 4 . The cumulative gains were derived as the total difference in gains between the CZP treatment and placebo groups and are presented over the 6-month period.

\section{RESULTS}

\section{Baseline characteristics}

A total of 409 patients were randomised and received at least one dose of study medication. Of these, 136 patients were randomised to placebo, 138 patients to CZP $200 \mathrm{mg}$ Q2W and 135 patients to CZP $400 \mathrm{mg}$ Q4W. A total of 368 patients $(90.0 \%)$ completed the 24-week placebo-controlled period; 59 placebo patients (43.4\%) underwent mandatory escape and were re-randomised to CZP treatment at week 16. Additionally, 18 (13.0\%) CZP $200 \mathrm{mg}$ Q2W and 21 (15.6\%) CZP $400 \mathrm{mg}$ Q4W patients fulfilled escape criteria, but continued randomised treatment with the same dose regimen as per protocol. ${ }^{21}$ Baseline demographics and characteristics, including measures of disease severity, were generally well balanced between treatment groups (table 1).

A total of $56.6 \%, 60.1 \%$ and $61.5 \%$ of patients in the placebo, CZP $200 \mathrm{mg}$ Q2W and CZP $400 \mathrm{mg}$ Q4W treatment

Table 2 RAPID-PsA: burden of PsA on productivity in the workplace and within the home at study baseline (RS population, observed cases)

\begin{tabular}{|c|c|c|c|c|c|c|c|c|}
\hline & \multicolumn{2}{|c|}{ Placebo } & \multicolumn{2}{|c|}{ CZP 200 mg Q2W } & \multicolumn{2}{|c|}{ CZP $400 \mathrm{mg}$ Q4W } & \multicolumn{2}{|c|}{ All patients } \\
\hline & Mean & Median & Mean & Median & Mean & Median & Mean & Median \\
\hline Productivity at the workplace over previous month (employed patients only) & \multicolumn{2}{|c|}{$n=77$} & \multicolumn{2}{|c|}{$n=83$} & \multicolumn{2}{|c|}{$n=83$} & \multicolumn{2}{|c|}{$n=243$} \\
\hline Work days missed due to arthritis & 2.6 & 0.0 & 2.0 & 0.0 & 1.6 & 0.0 & 2.0 & 0.0 \\
\hline Days with work productivity reduced by $\geq 50 \%$ due to arthritis* & 3.8 & 0.0 & 5.2 & 0.0 & 5.1 & 0.0 & 4.7 & 0.0 \\
\hline Rate of arthritis interference with work productivity ${ }^{\prime}$ & 4.2 & 5.0 & 4.4 & 5.0 & 3.8 & 4.0 & 4.1 & 5.0 \\
\hline Productivity at home and daily activities over previous month & \multicolumn{2}{|c|}{$n=136$} & \multicolumn{2}{|c|}{$n=138$} & \multicolumn{2}{|c|}{$n=135$} & \multicolumn{2}{|c|}{$n=409$} \\
\hline Days with no household work due to arthritis & 5.6 & 1.5 & 5.9 & 0.0 & 5.5 & 2.0 & 5.7 & 2.0 \\
\hline Days with household work productivity reduced by $\geq 50 \%$ due to arthritis* & 8.6 & 5.0 & 7.1 & 4.0 & 7.1 & 5.0 & 7.6 & 5.0 \\
\hline Days missed of family, social or leisure activities due to arthritis & 3.7 & 0.0 & 4.1 & 0.0 & 3.3 & 0.0 & 3.7 & 0.0 \\
\hline Days with outside help hired due to arthritis & 2.2 & 0.0 & 2.5 & 0.0 & 2.7 & 0.0 & 2.4 & 0.0 \\
\hline Rate of arthritis interference with household work productivity ${ }^{\dagger}$ & 4.9 & 5.0 & 5.2 & 5.0 & 4.9 & 5.0 & 5.0 & 5.0 \\
\hline
\end{tabular}


groups, respectively, were employed at study baseline. Among the RS population, $13.0-15.6 \%$ of the patients were unable to work due to PsA, 12.6-14.2\% were retired and 3.7-8.2\% were homemakers (figure 1).

\section{Burden of disease on workplace and household productivity at baseline}

Overall, the burden of disease at study baseline was high in PsA patients. Employed patients reported on average more than 1 week of workplace productivity (in terms of both absenteeism and presenteeism) affected by PsA over the previous month (table 2).

The burden of PsA on household productivity was even greater than that seen in the workplace, with on average more than 2 weeks of household work and social activities affected by the disease over the previous month. Baseline productivity was comparable across treatment arms (table 2).

\section{Improvements in workplace productivity}

At baseline, all patients answered at least one of the WPS questions; there were no patients with a completely missing WPS questionnaire. The beneficial effects of CZP treatment on workplace productivity compared with placebo were observed as early as week 4 and continued up to week 24 .

At week 4, employed patients in both CZP treatment arms had an average of $0.6-0.9$ fewer days of absenteeism per month, had 2.2-2.4 fewer days per month with reduced productivity and a reduced monthly rate of PsA interference with work productivity of $0.8-1.4$ (on a 0-10 scale), compared with an average 0.5 fewer days of absenteeism per month, 1.2 fewer days with

A Work days missed due to arthritis per month
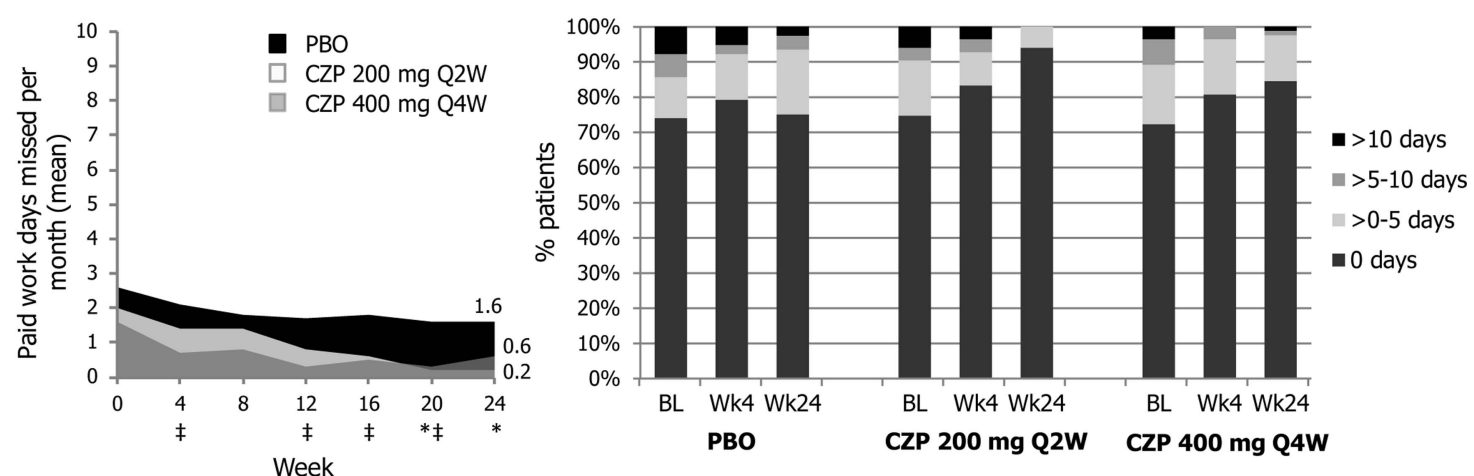

B Days with work productivity reduced by $\geq 50 \%$ due to arthritis per month
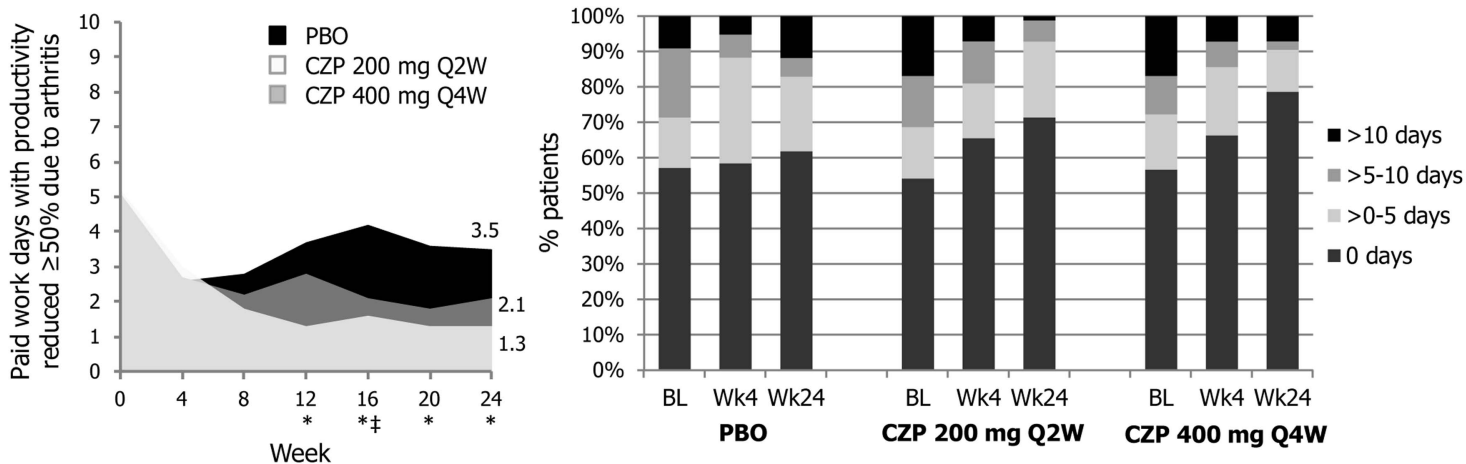

C Level of arthritis interference with work productivity per month ${ }^{\dagger}$
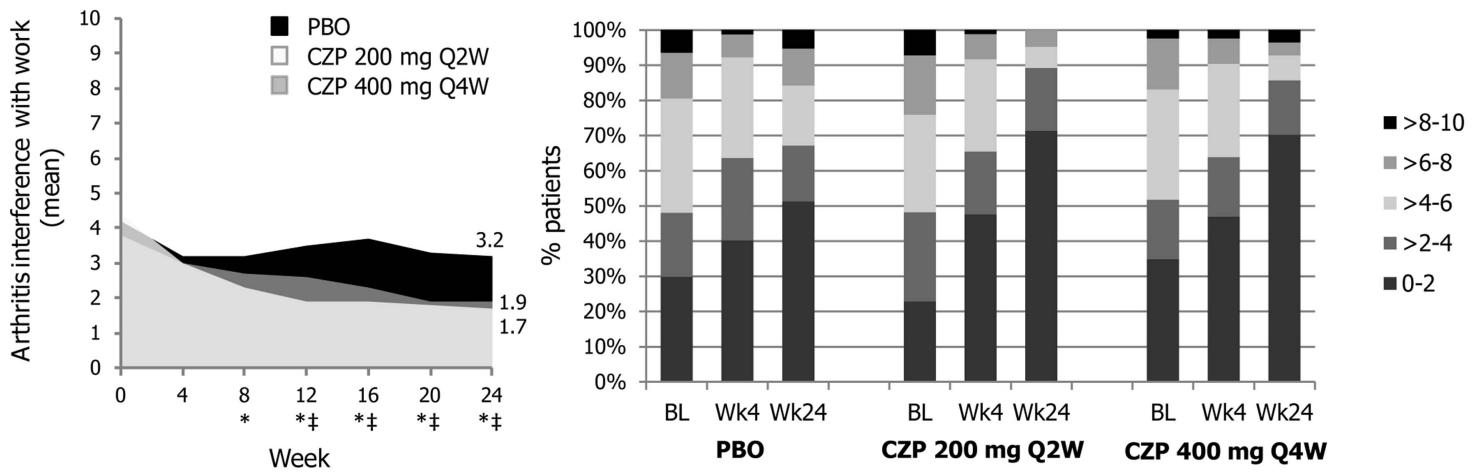

Figure 2 RAPID-PsA: monthly improvements in paid work productivity (employed patients, randomised set population). Left hand panels represent work productivity outcomes up to week 24, right hand panels represent frequency distribution plots at baseline (BL), week 4 and week 24 . Non-parametric bootstrap-t test, last observation carried forward. ${ }^{*}$ Certolizumab pegol (CZP) $200 \mathrm{mg}$ Q2W vs placebo (PBO) p-value $\leq 0.05$; $¥ C Z P$ $400 \mathrm{mg} \mathrm{Q4W}$ vs PBO $\mathrm{p}$-value $<0.05$; †0-10 point scale ( $0=$ no interference, $10=$ complete interference). 
Table 3 RAPID-PsA: improvements in productivity in the workplace and within the home at week 24 (RS population, LOCF)

\begin{tabular}{|c|c|c|c|c|c|}
\hline & Placebo & $\begin{array}{l}\text { CZP } 200 \mathrm{mg} \\
\text { Q2W }\end{array}$ & $\begin{array}{l}\text { CZP } 400 \mathrm{mg} \\
\text { Q4W }\end{array}$ & \multirow{3}{*}{$\begin{array}{l}\text { CZP } 200 \mathrm{mg} \\
\text { - Placebo } \\
\text { Mean diff } \\
\text { (95\% CI) } \\
\text { ( } p \text { value) }\end{array}$} & \multirow{2}{*}{$\begin{array}{l}\text { CZP } 400 \text { mg } \\
\text { - Placebo } \\
\text { Mean diff } \\
\text { (95\% CI) } \\
\text { (p value) }\end{array}$} \\
\hline & \multicolumn{3}{|c|}{ Mean } & & \\
\hline $\begin{array}{l}\text { Productivity at the workplace over previous month (employed patients } \\
\text { only) }\end{array}$ & $n=76$ & $n=84$ & $n=84$ & & \\
\hline Work days missed due to arthritis & 1.6 & 0.2 & 0.6 & $\begin{array}{l}-1.4(-3.4 \text { to }-0.6) \\
(<0.001)\end{array}$ & $\begin{array}{l}-1.0(-2.8 \text { to }-0.1) \\
(0.060)\end{array}$ \\
\hline Days with work productivity reduced by $\geq 50 \%$ due to arthritis* & 3.5 & 1.3 & 2.1 & $\begin{array}{l}-2.2(-4.1 \text { to }-0.7) \\
(0.003)\end{array}$ & $\begin{array}{l}-1.4(-3.4 \text { to } 0.6) \\
(0.176)\end{array}$ \\
\hline Rate of arthritis interference with work productivity $\dagger$ & 3.2 & 1.7 & 1.9 & $\begin{array}{l}-1.4(-2.3 \text { to }-0.7) \\
(<0.001)\end{array}$ & $\begin{array}{l}-1.2(-2.1 \text { to }-0.4) \\
(0.004)\end{array}$ \\
\hline Productivity at home and daily activities over previous month & $n=136$ & $n=138$ & $n=135$ & & \\
\hline Days with no household work due to arthritis & 4.7 & 2.5 & 2.4 & $\begin{array}{l}-2.3(-4.0 \text { to }-0.7) \\
(0.007)\end{array}$ & $\begin{array}{l}-2.2(-3.9 \text { to }-0.6) \\
(0.010)\end{array}$ \\
\hline $\begin{array}{l}\text { Days with household work productivity reduced by } \geq 50 \% \text { due to } \\
\text { arthritis* }\end{array}$ & 6.8 & 2.9 & 3.5 & $\begin{array}{l}-3.9(-5.8 \text { to }-2.2) \\
(<0.001)\end{array}$ & $\begin{array}{l}-3.4(-5.3 \text { to }-1.5) \\
(<0.001)\end{array}$ \\
\hline Days missed of family, social or leisure activities due to arthritis & 2.8 & 1.1 & 1.0 & $\begin{array}{l}-1.7(-3.1 \text { to }-0.5) \\
(0.005)\end{array}$ & $\begin{array}{l}-1.8(-3.2 \text { to }-0.6) \\
(0.004)\end{array}$ \\
\hline Days with outside help hired due to arthritis & 1.9 & 0.7 & 1.5 & $\begin{array}{l}-1.2(-2.4 \text { to }-0.3) \\
(0.008)\end{array}$ & $\begin{array}{l}-0.4(-1.7 \text { to } 1.0) \\
(0.582)\end{array}$ \\
\hline Rate of arthritis interference with household work productivity $\dagger$ & 4.1 & 2.2 & 2.6 & $\begin{array}{l}-1.8(-2.5 \text { to }-1.2) \\
(<0.001)\end{array}$ & $\begin{array}{l}-1.5(-2.1 \text { to }-0.8) \\
(<0.001)\end{array}$ \\
\hline
\end{tabular}

reduced productivity, and a reduced rate of PsA interference of 1.0 for placebo patients (figure 2). Improvements from baseline in CZP-treated patients were further increased up to week 24 of the RAPID-PsA study; an average of 1.0-1.8 fewer days of absenteeism per month, 3.0-3.9 fewer days per month with reduced productivity, and PsA interference with paid work productivity reduced by 1.9-2.7, compared with 1.0 less day of absenteeism per month $(\mathrm{p}<0.05$; CZP $200 \mathrm{mg}$ Q2W vs placebo), 0.3 fewer days per month with reduced productivity ( $\mathrm{p}<0.05$; CZP $200 \mathrm{mg}$ Q2W vs placebo), and PsA interference with work reduced by 1.0 in placebo patients $(\mathrm{p}<0.05$; either CZP arm vs placebo) (figure 2; see table 3 for mean difference and CI values).

At week 24, the number of CZP-treated patients who did not report workplace absenteeism increased by $12.2-19.3 \%$, compared with $1.0 \%$ in the placebo group. Similar frequency distribution patterns were seen for the number of paid work days with reduced productivity and the level of PsA interference with paid work productivity. These monthly improvements in workplace productivity reported by CZP-treated patients resulted in cumulative gains over the 24 weeks equivalent to a mean of 6.7 or 8.3 full days gained of paid work and an additional mean of 8.8 or 5.2 days with increased productivity for CZP $200 \mathrm{mg}$ Q2W or CZP 400 mg Q4W, respectively, over placebo.

\section{Improvements in productivity within the home and increased participation in family, social and leisure activities}

Regardless of employment status, CZP-treated patients reported reduced loss of productivity within the home and greater participation in daily activities compared to placebo patients. Improvements in household work productivity in CZP-treated patients were observed as early as week 4 and continued up to week 24 (figure 3).

At week 4, CZP-treated patients reported on average 1.9-2.2 fewer days with no household productivity per month, 1.8-1.9 fewer days per month with reduced household productivity, and a reduced monthly rate of PsA interference with work productivity of 1.4-1.6 (on a 0-10 scale), compared with 1.2 days gained per month, 1.9 fewer days with reduced productivity, and a reduced rate of PsA interference of 0.4 for patients in the placebo group (figure 3). Further improvements were reported in CZP-treated patients up to week 24 with an average of 3.0-3.5 fewer days with no household work, 3.6-4.2 fewer days with reduced household productivity, and PsA interference with productivity within the home reduced by 2.3-3.0, compared with an average of 1.0 less day with no household work per month ( $\mathrm{p}<0.05$; either CZP arm vs placebo), 1.8 fewer days per month with reduced productivity ( $\mathrm{p}<0.05$; either CZP arm vs placebo), and PsA interference with work reduced by 0.8 in placebo patients $(p<0.05$; either CZP arm vs placebo) (figure 3$)$. For CZP patients, improvements in participation in family, social and leisure activities were observed at week 24 with an average of 2.3-3.0 days gained per month, compared with just 0.9 days gained in placebo patients ( $\mathrm{p}<0.05$; either CZP arm vs placebo) (figure 3 ; see table 3 for mean difference and CI values).

The number of CZP patients with no days lost of household work was increased by $23.7-26.1 \%$ at week 24 , compared with an increase of $4.4 \%$ in the placebo group. Similar frequency distribution patterns were seen for the number of days with reduced household work productivity, the level of PsA interference with household work productivity, and the number of days missed of family, social and leisure activities.

Cumulative gains in full days of household work over placebo were equivalent to, on average, 10.5 and 12.9 days for CZP $200 \mathrm{mg}$ Q2W and CZP $400 \mathrm{mg}$ Q4W, respectively, over the 24-week period. CZP treated patients also gained over placebo an additional mean of 20.1 and 16.6 days, respectively, of productive household work over the 24 -week period and a mean of 5.1 and 7.4 days, respectively, of social, family or leisure activities over the 24 weeks. 
A Days with no household work due to arthritis

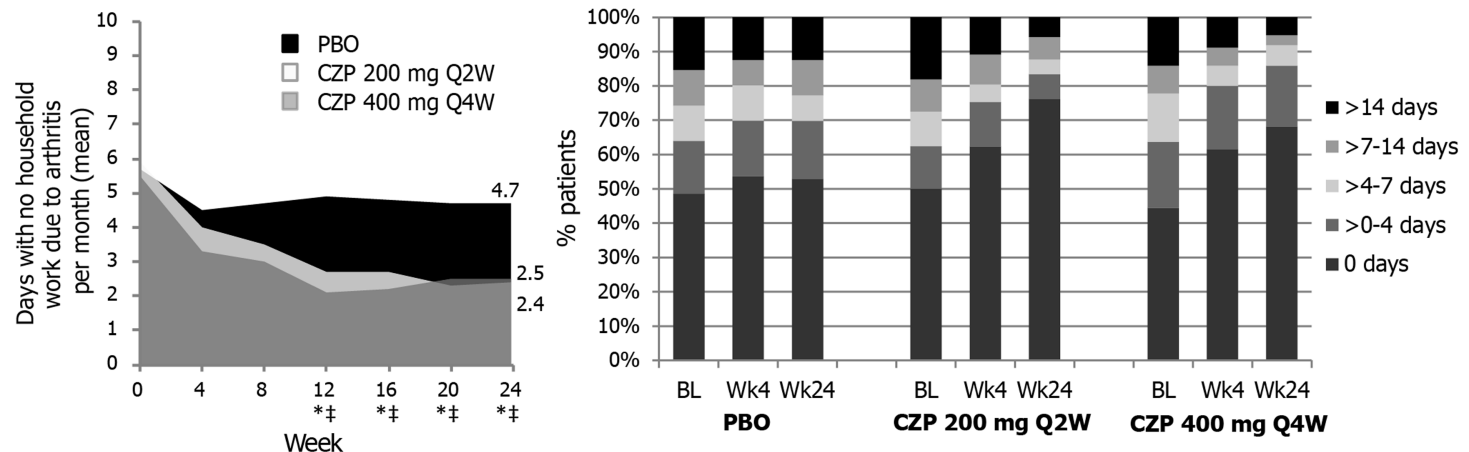

B Days with household work productivity reduced by $\geq 50 \%$ due to arthritis per month
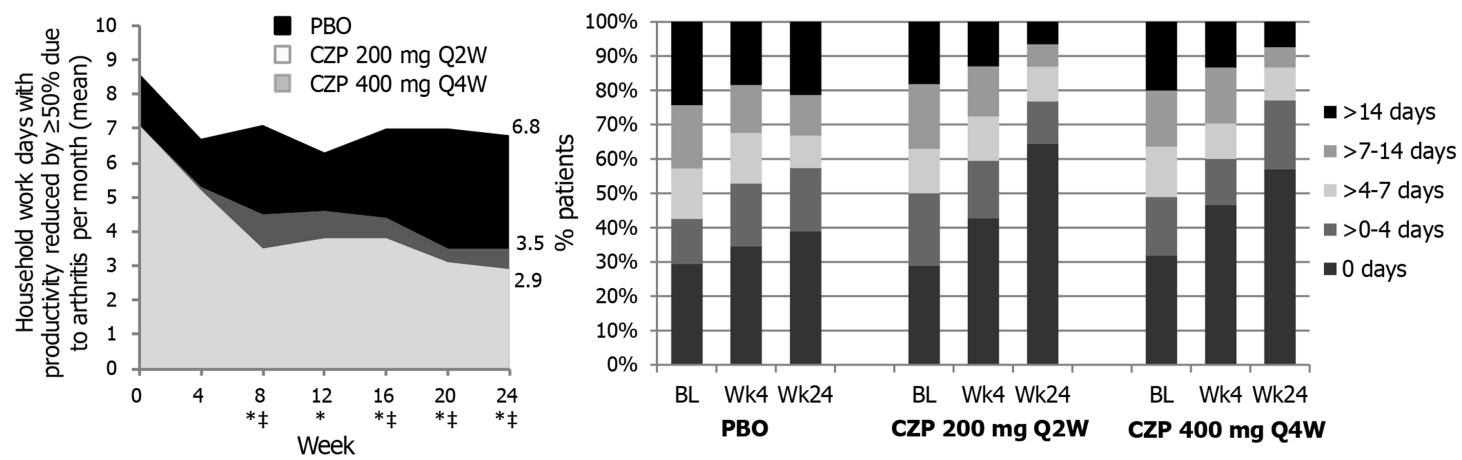

C Level of arthritis interference with household work productivity per month ${ }^{\dagger}$
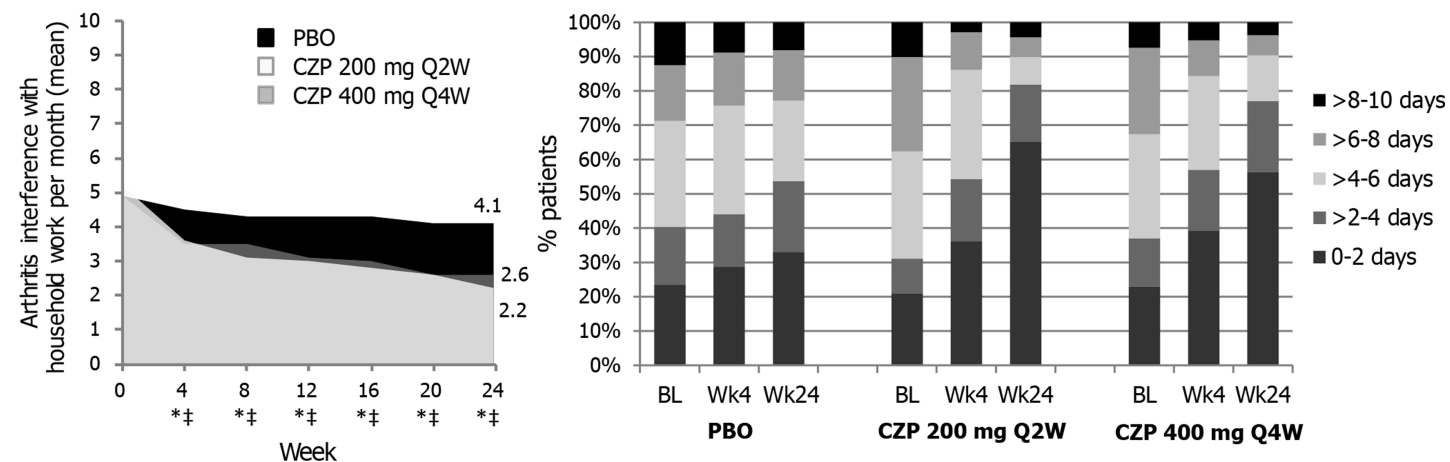

D Days missed of family, social and leisure due to arthritis per month ${ }^{\dagger}$
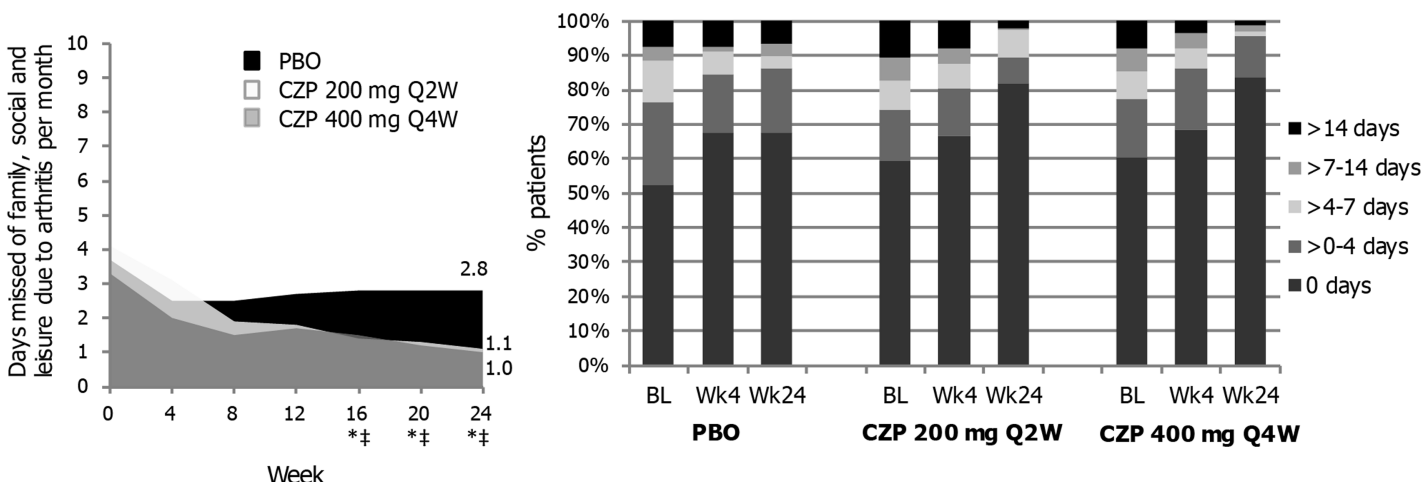

Figure 3 RAPID-PsA: monthly improvements in productivity within the household and in family, social and leisure activities (randomised set population). Left hand panels represent work productivity outcomes up to week 24, right hand panels represent frequency distribution plots at baseline (BL), week 4 and week 24. Non-parametric bootstrap-t test, last observation carried forward. * Certolizumab pegol (CZP) $200 \mathrm{mg}$ Q2W vs placebo (PBO) $p$-value $\leq 0.05 ; \neq C Z P 400 \mathrm{mg} \mathrm{Q4W}$ vs PBO $p$-value $<0.05$; †0-10 point scale ( $0=$ no interference, $10=$ complete interference). 


\section{DISCUSSION}

Baseline data from the RAPID-PsA trial suggest that PsA has a significant impact on employment status and productivity, both within and outside the home. These findings are consistent with previous reports of severe work disability and loss of productivity in PsA patients, ${ }^{9}$ including studies that report a reduced ability to work or volunteer, ${ }^{16}$ or to fulfil work, personal and social lives. ${ }^{17}$ Previous reports also suggest that patients with severe PsA may be forced into early retirement or unemployment due to an inability to perform physical work activities. ${ }^{29}$ However, compared with a large number of reports on the burden of RA on patient productivity, relatively little is known about the true negative impact of PsA on productivity. There is some evidence to suggest that the employment rate in PsA patients is higher than in the RA population, but significantly lower than that seen in the general population. ${ }^{15}$ However, age of onset of PsA is in the 30-40s for men and women, an age at which many patients are in the midst of their working careers. Thus, the earlier onset of disease in PsA, compared with RA, could result in greater disability over the course of a PsA patient's working life and may impact significantly on career progression.

The financial burden of PsA is likely to be significant and includes both direct costs associated with the provision of healthcare, and indirect costs associated with loss of productivity, due to time off work for medical care, lost wages from time off, decreased productivity at work and unemployment due to disability. ${ }^{29}$ Previous papers have reported large indirect economic costs associated with PsA in terms of costs associated with patients' short-term absence from work, patients' permanent work disability and caregivers' short-term absence from work. ${ }^{30-32}$ As the indirect costs attributed to lost productivity in the workplace and at home are major contributors to the economic burden of PsA, any improvements in productivity associated with CZP treatment will help reduce the economic burden of this chronic inflammatory disease.

In the RAPID-PsA study, CZP treatment resulted in rapid and substantial improvements in workplace and household productivity. Improved productivity at work and within the home was seen as early as week 4 and continued up to week 24 . This included reduced absenteeism and presenteeism for employed patients in both CZP groups, compared with placebo. CZP treatment also resulted in improved productivity within the home, and fewer days of lost participation in family, social and leisure activities per month. These results, alongside clinical improvements seen over the first 24 weeks of CZP treatment in PsA patients, ${ }^{21}$ indicate that CZP may be a valuable treatment option for PsA patients. Improvements in productivity may also contribute to the patients' psychosocial well-being, enhancing these additional aspects of their health-related quality of life.

In line with the current PsA study, CZP plus methotrexate (MTX) has previously been shown to improve productivity in RA patients both outside and within the home. The combination therapy also resulted in greater participation in social activities compared with placebo plus MTX. ${ }^{33}$ Other TNF inhibitors, namely etanercept, infliximab and golimumab, have also been shown to improve productivity in patients with active PsA. ${ }^{18-20}$ However, differences in the measures used to assess the impact of specific treatments on productivity make it difficult to compare between specific TNF inhibitors.

A limitation of the current report is that it only presents results up to week 24 of the RAPID-PsA trial. Consequently, longer-term results from this study or from real-life observational studies will be needed to confirm these initial findings. This is important as currently there is limited evidence from long-term observational studies in terms of the benefits of anti-TNFs on work disability in PsA. ${ }^{94}$ Other limitations of the data reported here include the early withdrawal of some patients (prior to week 24) and use of LOCF methodologies to impute any missing data. Nevertheless, the data reveal a rapid effect of CZP treatment, with improvements seen within 4 weeks of administration, in both CZP dosing regimens (CZP $200 \mathrm{mg}$ Q2W and CZP $400 \mathrm{mg}$ Q4W) across a broad spectrum of productivity-related concepts.

In summary, PsA had a significant burden on patient productivity at study baseline. The rapid improvements seen in CZP-treated patients in paid work productivity, household productivity and participation in family, social and leisure activities, alongside the clinical improvements seen, suggest that CZP is a potentially valuable treatment option for PsA patients. These beneficial effects with respect to PsA patients' workplace and household productivity could ultimately result in gains in the quality of life and in the economic burden of this chronic inflammatory disease, particularly in those of working age.

Acknowledgements The authors acknowledge Marine Champsaur, UCB Pharma, Brussels, Belgium for publication coordination and Costello Medical Consulting, UK, for writing and editorial assistance, which was funded by UCB Pharma.

Contributors All authors were involved in planning for the analysis of data, reviewed the primary data, reviewed and approved each draft of the manuscript including approval of the final version.

Funding The RAPID-PSA study was funded by UCB Pharma.

Competing interests AK has received research grants from Abbott, Amgen, BMS, Pfizer, Roche, Janssen, UCB Pharma. DG has received research grants and/or consulting fees from Abbott, BMS, Celgene, Johnson \& Johnson, MSD, Novartis, Pfizer, UCB Pharma. DvdH has received research grants and/or consulting fees from AbbVie, Amgen, AstraZeneca, Augurex, BMS, Celgene, Centocor, Chugai, Covagen, Daiichi, Eli-Lilly, GSK, Janssen, Merck, Novartis, Novo-Nordisk, Otsuka, Pfizer, Roche, Sanofi-Aventis, Schering-Plough, UCB Pharma, Vertex and is the Director of Imaging Rheumatology bv. OP is an employee of UCB Pharma. PM has received research grants, speaker's fees or consulting fees from Abbott, AbbVie, Amgen, Biogenldec, BMS, Celgene, Crescendo, Eli-Lilly, Genentech, Janssen, Merck, Novartis, Pfizer, UCB Pharma, Vertex.

\section{Patient consent Obtained.}

Ethics approval National and Regional Ethics Committee or Institutional Review Board (Global Study).

Provenance and peer review Not commissioned; externally peer reviewed.

Open Access This is an Open Access article distributed in accordance with the Creative Commons Attribution Non Commercial (CC BY-NC 3.0) license, which permits others to distribute, remix, adapt, build upon this work non-commercially, and license their derivative works on different terms, provided the original work is properly cited and the use is non-commercial. See: http://creativecommons.org/ licenses/by-nc/3.0/

\section{REFERENCES}

1 Dhir V, Aggarwal A. Psoriatic arthritis: a critical review. Clin Rev Allergy Immunol 2013;44:141-8

2 Haroon M, Kirby B, Fitzgerald 0 . High prevalence of psoriatic arthritis in patients with severe psoriasis with suboptimal performance of screening questionnaires. Ann Rheum Dis 2013;72:736-40.

3 Mease PJ, Gladman DD, Papp KA, et al. Prevalence of rheumatologist-diagnosed psoriatic arthritis in patients with psoriasis in European/North American dermatology clinics. J Am Acad Dermatol 2013;69:729-35.

4 Alonso JCT, Perez AR, Castrillo JMA, et al. Psoriatic arthritis (PA): a clinical, immunological and radiological study of 180 patients. Rheumatology (Oxford) 1991;30:245-50

5 Kane D, Stafford L, Bresnihan B, et al. A prospective, clinical and radiological study of early psoriatic arthritis: an early synovitis clinic experience. Rheumatology (Oxford) 2003:42:1460-8.

6 McHugh NJ, Balachrishnan C, Jones SM. Progression of peripheral joint disease in psoriatic arthritis: a 5-yr prospective study. Rheumatology (Oxford) 2003:42:778-83.

7 Gladman DD, Antoni C, Mease $\mathrm{P}$, et al. Psoriatic arthritis: epidemiology, clinical features, course, and outcome. Ann Rheum Dis 2005;64(Suppl 2):ii14-17. 
8 Rosen CF, Mussani F, Chandran V, et al. Patients with psoriatic arthritis have worse quality of life than those with psoriasis alone. Rheumatology 2012;51:571-6.

9 Tillett W, de-Vries C, McHugh NJ. Work disability in psoriatic arthritis: a systematic review. Rheumatology (Oxford) 2012;51:275-83.

10 Boonen A, Mau W. The economic burden of disease: comparison between rheumatoid arthritis and ankylosing spondylitis. Clin Exp Rheumatol 2009;27(4 Suppl 55):S112-17.

11 Chaparro Del Moral R, Rillo OL, Casalla L, et al. Work productivity in rheumatoid arthritis: relationship with clinical and radiological features. Arthritis 2012;2012:137635.

12 Zhang W, Anis AH. The economic burden of rheumatoid arthritis: beyond health care costs. Clin Rheumatol 2011;30(Suppl 1):S25-32.

13 Boonen A, van der Heijde D. Review of the costs of illness of ankylosing spondylitis and methodologic notes. Expert Rev Pharmacoecon Outcomes Res 2005; 5:163-81.

14 Wallenius M, Skomsvoll JF, Koldingsnes W, et al. Work disability and health-related quality of life in males and females with psoriatic arthritis. Ann Rheum Dis 2009;68:685-9.

15 Mau W, Listing J, Huscher D, et al. Employment across chronic inflammatory rheumatic diseases and comparison with the general population. J Rheumatol 2005:32:721-8.

16 Hu SW, Holt EW, Husni ME, et al. Willingness-to-pay stated preferences for 8 health-related quality-of-life domains in psoriatic arthritis: a pilot study. Semin Arthritis Rheum 2010;39:384-97.

17 McKenna SP, Doward LC, Whalley D, et al. Development of the PSAQoL: a quality of life instrument specific to psoriatic arthritis. Ann Rheum Dis 2004;63:162-9.

18 Gladman DD, Bombardier C, Thorne C, et al. Effectiveness and safety of etanercept in patients with psoriatic arthritis in a Canadian clinical practice setting: the REPArE trial. J Rheumatol 2011;38:1355-62.

19 Kavanaugh A, Antoni $C$, Mease $P$, et al. Effect of infliximab therapy on employment, time lost from work, and productivity in patients with psoriatic arthritis. J Rheumatol 2006;33:2254-9.

20 Kavanaugh A, Mclnnes IB, Krueger GG, et al. Patient-reported outcomes and the association with clinical response in patients with active psoriatic arthritis treated with golimumab: Findings through 2 years of a phase III, multicentre, randomized, double-blind, placebo-controlled trial. Arthritis Care Res (Hoboken) 2013:65:1666-73.

21 Mease PJ, Fleischmann R, Deodhar AA, et al. Effect of certolizumab pegol on signs and symptoms in patients with psoriatic arthritis: 24-week results of a phase 3 double-blind randomized placebo-controlled study (RAPID-PsA). Ann Rheum Dis 2014;73:48-55.
22 Taylor W, Gladman D, Helliwell P, et al. Classification criteria for psoriatic arthritis: development of new criteria from a large international study. Arthritis Rheum 2006;54:2665-73.

23 van der Heijde D, Fleischmann R, Wollenhaupt J, et al. Effect of different imputation approaches on the evaluation of radiographic progression in patients with psoriatic arthritis: results of the RAPID-PSA 24-week phase 3 double-blind randomised placebo-controlled study of certolizumab pegol. Ann Rheum Dis 2014;73:233-7.

24 Osterhaus JT, Purcaru O, Richard L. Discriminant validity, responsiveness and reliability of the rheumatoid arthritis-specific Work Productivity Survey (WPS-RA). Arthritis Res Ther 2009;11:R73.

25 Osterhaus JT, Purcaru 0. Validity, responsiveness and reliability of the arthritis-specific work productivity survey assessing work productivity within and outside the home in subjects with psoriatic arthritis. Ann Rheum Dis 2013;72: 1025.

26 Osterhaus JT, Purcaru 0. Discriminant validity, responsiveness and reliability of the arthritis-specific Work Productivity Survey assessing workplace and household productivity in patients with psoriatic arthritis. Arthritis Res Ther 2014; In Press.

27 Gladman D, Fleischmann R, Coteur G, et al. Effect of certolizumab pegol on multiple facets of psoriatic arthritis as reported by patients: 24-week patient-reported outcome results of the RAPID-PSA study. Arthritis Care Res 2013. doi:10.1002/acr.22256

28 Barber JA, Thompson SG. Analysis of cost data in randomized trials: an application of the non-parametric bootstrap. Stat Med 2000;19:3219-36.

29 Mease PJ, Menter MA. Quality-of-life issues in psoriasis and psoriatic arthritis: outcome measures and therapies from a dermatological perspective. J Am Acad Dermatol 2006;54:685-704.

30 Huscher D, Merkesdal S, Thiele K, et al. Cost of illness in rheumatoid arthritis, ankylosing spondylitis, psoriatic arthritis and systemic lupus erythematosus in Germany. Ann Rheum Dis 2006;65:1175-83.

31 Moreno J, Dauden E, Rodríguez-Valverde V, et al. A cost of-illness study of psoriatic arthritis in Spain. Value in Health 2009;12:A437.

32 Olivieri I, de Portu S, Salvarani C, et al. The psoriatic arthritis cost evaluation study: a cost-of-illness study on tumour necrosis factor inhibitors in psoriatic arthritis patients with inadequate response to conventional therapy. Rheumatology (Oxford) 2008:47:1664-70.

33 Kavanaugh A, Smolen JS, Emery P, et al. Effect of certolizumab pegol with methotrexate on home and work place productivity and social activities in patients with active rheumatoid arthritis. Arthritis Rheum 2009;61:1592-600.

34 Lubrano E, Spadaro A. Pharmacoeconomic burden in the treatment of psoriatic arthritis: from systematic reviews to real clinical practice studies. BMC Musculoskelet Disord 2014;15:25. 